\title{
Renal ${ }^{123}$ I-MIBG Uptake before and after Live-Donor Kidney Transplantation
}

\author{
Thomas Rasmussen ${ }^{1, *}$, Robin de Nijs ${ }^{1}$ (D), Lene Kjær Olsen ${ }^{2}$, Anne-Lise Kamper ${ }^{2}$, \\ Lia Evi Bang ${ }^{3}$, Marie Frimodt-Møller ${ }^{4}$, Henning Kelbæk ${ }^{5}$, Søren Schwartz Sørensen ${ }^{2,6}$, \\ Andreas Kjær 1,6 ${ }^{D}$, Bo Feldt-Rasmussen ${ }^{2,6}$, Jesper Hastrup Svendsen ${ }^{3,6}(\mathbb{D}$ and Philip Hasbak 1 \\ 1 Departments of Clinical Physiology, Nuclear Medicine \& PET and Cluster for Molecular Imaging, \\ Copenhagen University Hospital, Rigshospitalet, 2100 Copenhagen, Denmark; \\ robin.de.nijs@regionh.dk (R.d.N.); andreas.kjaer@regionh.dk (A.K.); philip.hasbak@regionh.dk (P.H.) \\ 2 Department of Nephrology, Copenhagen University Hospital, Rigshospitalet, 2100 Copenhagen, Denmark; \\ lenekjaerolsen@gmail.com (L.K.O.); anne-lise.kamper@regionh.dk (A.-L.K.); \\ soeren.schwartz.soerensen@regionh.dk (S.S.S.); bo.feldt-rasmussen@regionh.dk (B.F.-R.) \\ 3 Department of Cardiology, Copenhagen University Hospital, Rigshospitalet, 2100 Copenhagen, Denmark; \\ lia.evi.bang@regionh.dk (L.E.B.); jesper.hastrup.svendsen@regionh.dk (J.H.S.) \\ 4 Steno Diabetes Center, Gentofte University Hospital, 2820 Gentofte, Denmark; \\ marie.frimodt-moeller@regionh.dk \\ 5 Department of Cardiology, Zealand University Hospital, 4000 Roskilde, Denmark; h.kelbaek@dadlnet.dk \\ 6 Department of Clinical Medicine, Faculty of Health and Medical sciences, University of Copenhagen, \\ 2100 Copenhagen, Denmark \\ * Correspondence: drrasmussen@hotmail.com
}

Received: 26 August 2020; Accepted: 7 October 2020; Published: 9 October 2020

\begin{abstract}
Increased sympathetic activity is suggested to be part of the pathogenesis in several diseases. Methods to evaluate sympathetic activity and renal nervous denervation procedural success are lacking. Scintigraphy using the norepinephrine analog Iodine-123 Metaiodobenzylguanidine (123I-MIBG) might provide information on renal sympathetic nervous activity. Renal transplantation induces complete denervation of the kidney and as such represents an ideal model to evaluate the renal ${ }^{123}$ I-MIBG scintigraphy method. The aim of this study was to evaluate whether renal ${ }^{123}$ I-MIBG scintigraphy can detect changes in renal sympathetic nervous activity following renal transplantation. Renal ${ }^{123}$ I-MIBG scintigraphy was performed in eleven renal transplant recipients at 1, 3, and 6 months following transplantation and in their respective living donors prior to their kidney donation. Relative uptake as well as washout was obtained. In transplanted patients, the relative $4 \mathrm{~h}$ uptake of ${ }^{123}$ I-MIBG, as measured by the kidney/background ratio, was 2.7 (0.4) (mean (SD)), $2.7(0.5)$, and $2.5(0.4)$ at 1, 3, and 6 months post-transplantation, respectively, as compared with the $4.0(0.4)$ value in the donor kidney before donor nephrectomy $(p<0.01)$. There was no significant change in washout-rate between pre-transplantation and any of the follow-up time points. Living donor kidney transplantation was at 6 months post transplantation, associated with an almost $40 \%$ reduction in the relative $4 \mathrm{~h}^{123} \mathrm{I}$-MIBG uptake of the kidney. Further studies will help to fully establish its implications as a marker of renal innervation or denervation.
\end{abstract}

Keywords: renal nervous activity; ${ }^{123}$ I-MIBG scintigraphy; renal transplantation; sympathetic nervous system; live kidney donor

\section{Introduction}

The activity of sympathetic renal nerves plays an important role in chronic kidney disease [1-3], renal transplantation [4-6], and in hypertension when hypertension is treated by renal denervation [7-9]. 
Stimulation of renal efferent sympathetic nerves increases sodium retention and renin release and reduces renal blood flow $[10,11]$.

Iodine-123 Metaiodobenzylguanidine $\left({ }^{123} \mathrm{I}-\mathrm{MIBG}\right)$ is an analog to norepinephrine and is taken up by the uptake-1 transport mechanism, also known as the norepinephrine transporter, in the presynaptic nerve terminal, and it is stored in the neurosecretory granules, resulting in a higher concentration compared with that in cells of tissues with lower sympathetic activity [12-14] (Figure 1). ${ }^{123}$ I-MIBG is predominantly excreted as an unchanged compound by the kidneys, with a rapid initial clearance followed by an almost constant plasma level between 1 and $24 \mathrm{~h}$ after injection of ${ }^{123}$ I-MIBG [15-17]. ${ }^{123} \mathrm{I}-\mathrm{MIBG}$ is a substrate of renal organic cation transporters, suggesting that it undergoes tubular secretion [18]. Therefore, renal ${ }^{123}$ I-MIBG is composed of four components: vascular, urinary, parenchymal, and neuronal. The radioactive labeling of ${ }^{123} \mathrm{I}-\mathrm{MIBG}$ enables scintigraphic imaging of presynaptic anatomy and function. ${ }^{123}$ I-MIBG is used clinically for diagnosis and localization of pheochromocytoma [19] and has been proposed as a prognostic marker in chronic heart failure [20].

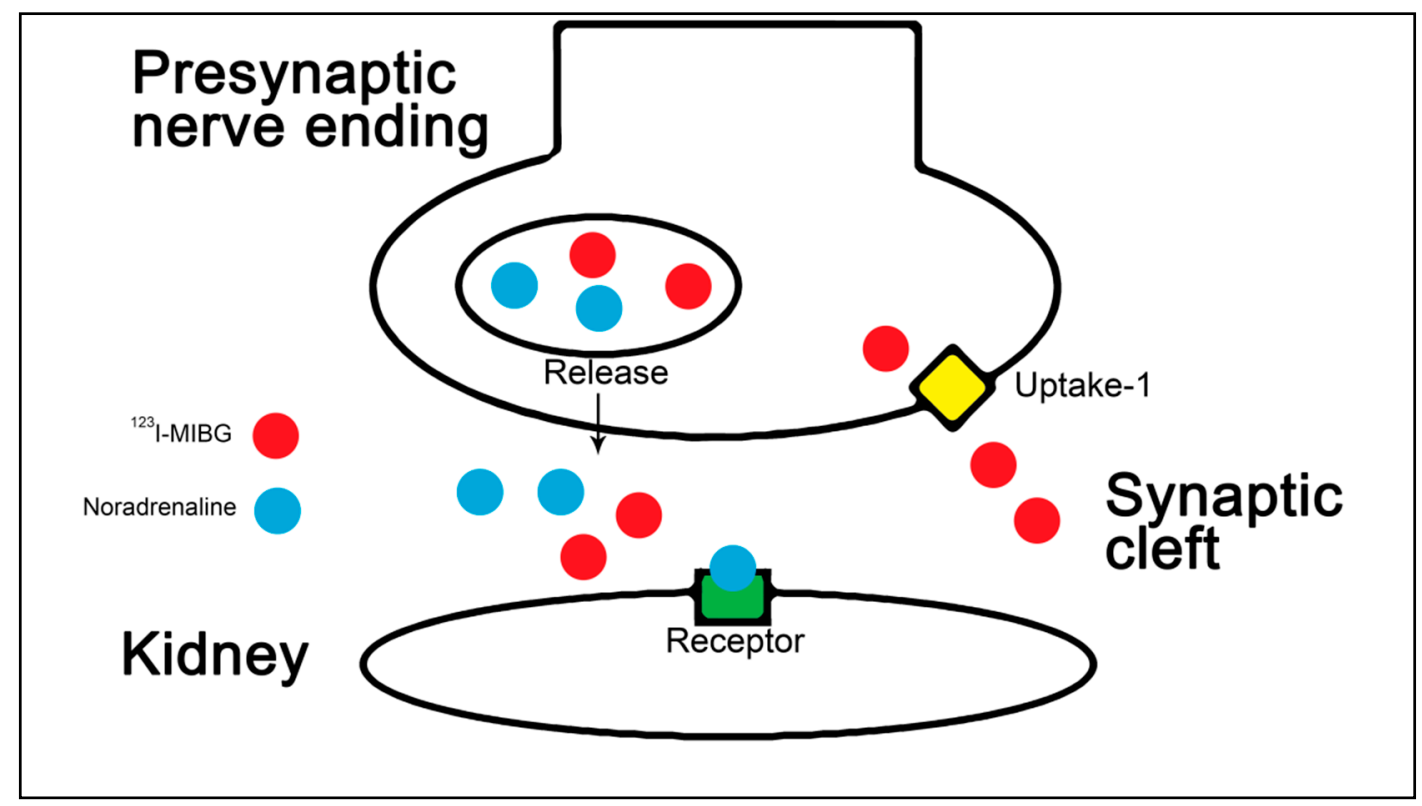

Figure 1. Iodine-123 Metaiodobenzylguanidine ( $\left.{ }^{123} \mathrm{I}-\mathrm{MIBG}\right)$ uptake and release. The figure illustrates how ${ }^{123} \mathrm{I}-\mathrm{MIBG}$ in the presynaptic nerve terminal is taken up via the uptake- 1 transport mechanism, stored as granules within vesicles, and then released. The scintigraphic measurement over the kidney at different time points provides information regarding the early uptake and the functionality.

${ }^{123}$ I-MIBG uptake supposedly visualizes reinnervation over time in heart transplant patients [21], and renal tracer activity has been demonstrated in patients with severe renal artery stenosis or renal artery compression [22,23]. A study of renal ${ }^{123}$ I-MIBG scintigraphy performed in 12 kidney transplant recipients has shown an association between time from transplantation and renal ${ }^{123}$ I-MIBG uptake parameters, suggesting functional re-innervation [24]. In a case-study of a fibromuscular dysplasia-induced renal artery stenosis, the relative ${ }^{123}$ I-MIBG uptake in the auto transplanted kidney was reduced by $30 \%$ at 2 weeks after the procedure [25]. In another study of renal ${ }^{123}$ I-MIBG scintigraphy performed before and six weeks after renal denervation for treatment of treatment-refractory essential hypertension, there was no significant change in renal ${ }^{123}$ I-MIBG relative uptake or washout [26]. Neuroanatomically, following the nerve transection that occurs in kidney transplantation, the distal part of the detached axon undergoes a Wallerian degeneration, which is a rapid, within days, fragmentation and cytoskeletal breakdown that occurs along the full length of the axon; however, overall, the periaxonal structure is maintained [27,28]. It is known that re-innervation of transplanted kidneys occurs, and partial reinnervation has been confirmed in histological studies [5,6]. In human 
renal allografts, surgically removed or post-mortem, histological evidence of axon regeneration was evident already 8 months after transplantation [6], whereas the degree of functionality of this regeneration of axons is questionable [4].

The aim of this study was to evaluate whether renal ${ }^{123}$ I-MIBG could detect any changes in renal sympathetic nervous activity following renal transplantation from living donors. Our hypothesis was that the denervated transplanted kidney would display a markedly reduced ${ }^{123}$ I-MIBG uptake compared to that found pre-transplantation.

\section{Materials and Methods}

\subsection{Subjects}

We prospectively included renal transplantation recipients $(n=11)$ and their respective live donors prior to kidney transplantation at Copenhagen University Hospital, Rigshospitalet, Denmark, from April 2014 to May 2015. Whereas 41 live kidney transplantations were performed in that period, limitation of the capacity to perform ${ }^{123}$ I-MIBG scintigraphy restricted us to invite only 18 donor/ recipient duos to participate, whereof 5 declined the invitation and 2 had their transplantation canceled. It was a clinical decision not to pause medication that could potentially influence ${ }^{123}$ I-MIGB uptake such as beta-blockers, calcium channel blockers, etc. Inclusion criteria were age $\geq 18$ years, eligibility for kidney donation/transplantation (donor/recipient in pairs) and clinically stable condition. Reason for withdrawal during the study was suspicion of or confirmation of acute rejection of the transplanted kidney at the follow-up time points.

\subsection{Ethics}

The study was approved by the Scientific-Ethics Committee for the Capital Region of Denmark (H-3-2013-190) and the Danish Data Protection Agency (30-1311), approved on 15th of January 2014. All participants signed informed consent forms prior to inclusion.

\subsection{Image Acquisition}

Renal ${ }^{123}$ I-MIBG scintigraphy was performed in donors prior to transplantation and in their respective recipients 1,3 , and 6 months after renal transplantation. Thyroid iodine uptake was blocked before injection of ${ }^{123} \mathrm{I}-\mathrm{MIBG}$ by oral administration of potassium perchlorate $(150 \mathrm{mg})$. Rest planar and SPECT/CT imaging were performed sequentially beginning approximately $15 \mathrm{~min}$ post-injection of 300-350 MBq ${ }^{123}$ I-MIBG (AdreView ${ }^{\text {TM }}$, GE Healthcare, Eindhoven, The Netherlands) followed by planar imaging at 1,2, and $4 \mathrm{~h}$ post-injection. Due to the practical clinical workflow, subjects were scanned either in a dual head 16-slice Precedence single-photon emission computed tomography (SPECT)/multi-detector CT (MDCT), (Philips Medical Systems, Best, The Netherlands) or a dual head Symbia T16 SPECT/CT scanner (Siemens, Erlangen, Germany) with a $9.5 \mathrm{~mm}$ thick scintillation crystal. In the following sections, Philips and Siemens parameters will be stated, and if different, they will be separated by a slash. ${ }^{123}$ I-MIBG was imaged with a standard Anger camera using a medium-energy general purpose collimator/low penetration, MEGP/MELP, to reduce the contribution of high-energy ${ }^{123}$ I photon emissions, especially those at $529 \mathrm{keV}$ to penetrate collimator septa [29,30]. The energy window was set at $159 \mathrm{keV}$ with a width of $20 \% / 15 \%$. The acquisition protocol on the scanner consisted of a ten minutes planar acquisition (arms down) with matrix size $256 \times 256$ and 2.332/2.398 mm pixel size. Later planar acquisitions were acquired with the same settings, but with slightly different patient position. SPECT data was acquired in a $128 \times 128$ matrix with a pixel size of $4.664 / 4.796 \mathrm{~mm}$ at 128 angles (20 s each) in step-and-shoot mode. A low dose CT scan of the same region was acquired with $5 \mathrm{~mm}$ thick slices in a $512 \times 512$ matrix with a pixel size of $1.172 / 0.977 \mathrm{~mm}$ at $140 / 130 \mathrm{kV}$. 


\subsection{Image Processing and Interpretation}

The washout rate not only assesses the ability of the kidney to retain the tracer but may also reflect competition for the uptake- 1 transport mechanism by circulating norepinephrine. The early kidney/background ratio reflects receptor density and likely portrays the integrity of presynaptic nerve terminals and uptake-1 function. ${ }^{123}$ I-MIBG SPECT data was reconstructed using Astonish/Flash3D, Philips Healthcare, Best, The Netherlands. Regions of interest (ROIs) were drawn over the kidney(s) and background on planar images, see Figure 2.

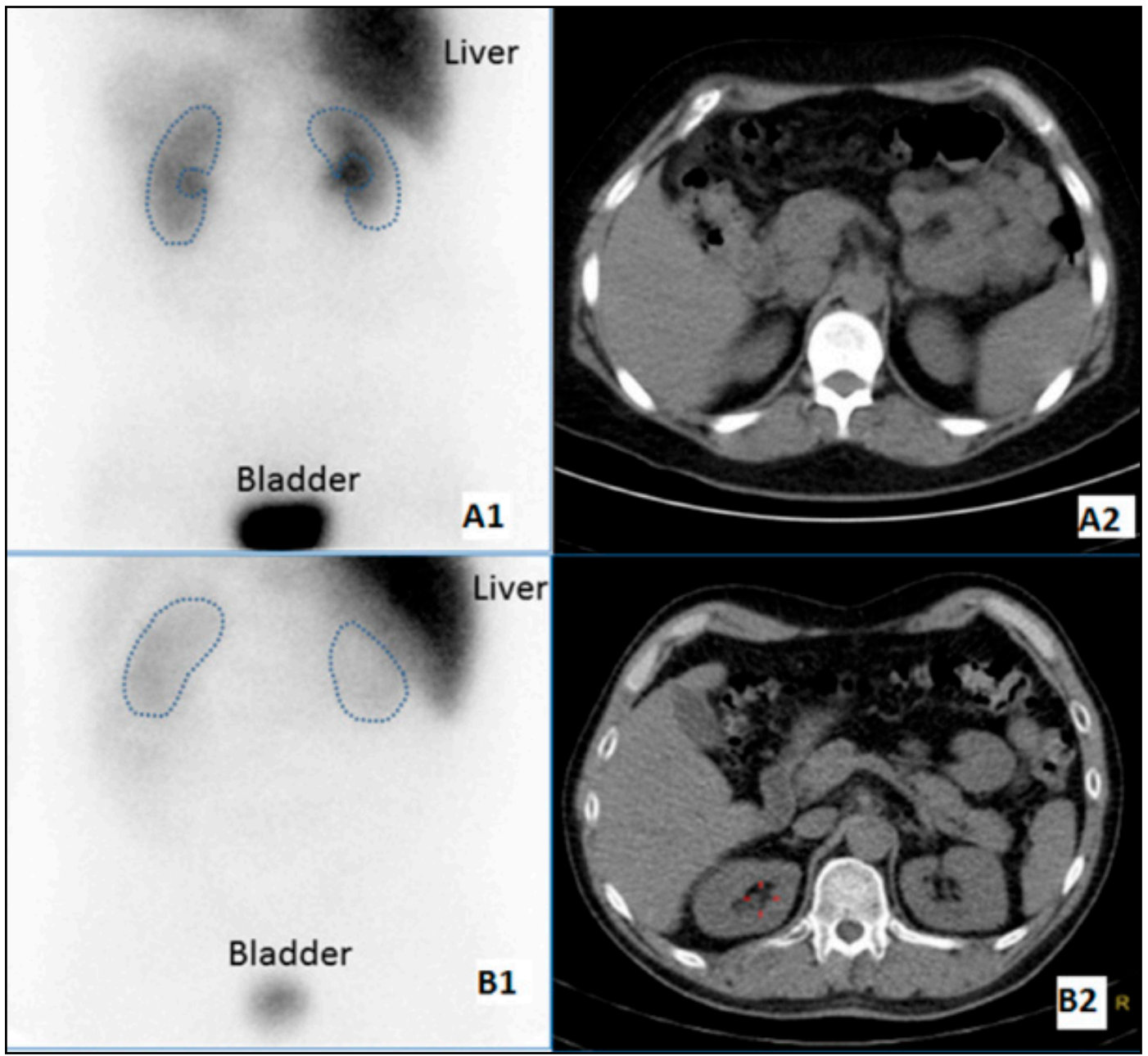

Figure 2. Scintigraphic visualization of ${ }^{123} \mathrm{I}-\mathrm{MIBG}$ uptake. The figure illustrates the challenge when using 2D-planar recording for drawing of regions of interest (ROIs). In (A1,A2), the right kidney is anatomically free of the liver, while the right kidney is covered by the liver in (B1). By using SPECT/CT for ROI drawing in (A1,B2), this overlap could be avoided (Red crosshair in (B2) marks the right renal pelvis). The presence of renal pelvic activity in (A1) (although excluded on the ROIs) makes it evident that substantial counts are due to excretory activity.

Since the anatomical position of the kidney was different within the donor and the recipient, attenuation correction needed to be applied to enable a correct comparison of the exact same anatomical structure. An experienced nuclear physician processed all images for this study. Renal ${ }^{123}$ I-MIBG uptake was calculated by using mean counts per pixel obtained by manually drawn ROIs. The gluteal muscles served as reference tissue. ${ }^{123}$ I-MIBG image interpretation consists of quantitation of global kidney tracer uptake in reference to gluteal muscle ratio, kidney/background ratio, and retention of tracer between early and late images, that is, washout rate and regional uptake on SPECT images. 
The relative ${ }^{123}$ I-MIBG uptake was quantified by calculating the kidney/background ratio at $15 \mathrm{~min}$ (early), 1, 2, and $4 \mathrm{~h}$ (late) post tracer injection:

$$
\frac{\text { kidney }}{\text { background }} \text { ratio }=\frac{\text { kidney }(\text { specific })}{\text { muscle }(\text { non }- \text { specific })}
$$

The washout rate between two time points following the ${ }^{123}$ I-MIBG infusion can be calculated by:

$$
\begin{gathered}
\text { Washout rate }(\% \text { per hour })=\left(\frac{\ln \left(\frac{\text { kidney ROI count } \mathrm{t}_{\mathrm{t}}=1}{\text { kidney ROI coun } \mathrm{t}=2_{2}}\right)}{\mathrm{t} 2-\mathrm{t} 1}-\frac{\ln (2)}{\mathrm{T}}\right) * 100 \% \\
\mathrm{~T} \text { for }{ }^{123} \mathrm{I}-\mathrm{MIBG}=13.2 \mathrm{~h}
\end{gathered}
$$

\subsubsection{Attenuation Correction}

Attenuation correction (AC) was applied by utilizing the CT scan obtained together with the SPECT acquisition of approximately the same region of the patient. Further details of the AC can be found in Appendix A.

\subsubsection{Alignment}

The patient remained in the same position during acquisition of the first planar image and the SPECT-CT acquisition. This allowed positioning parameters in the Digital Imaging and Communications in Medicine (DICOM) header to align the CT with the first planar image for the Philips images. Positioning information could not be stored on the Siemens scanner; therefore, the CT and planar images were aligned from the assumption that $\mathrm{CT}$ and planar images had identical image centers. The CT-based images ( $T_{\text {water }}$ and AC) were interpolated to match the pixel size of the planar images. Subsequent planar images were acquired with alignment to the first planar image by manually choosing three characteristic landmarks such as edges and notches on the anterior, posterior, and geometric mean image on both the first image and the image to be aligned. The precision of this procedure was indicated by the sample standard deviation of the mean transformation, which was less than $3 \mathrm{~mm}$ for every alignment.

\subsection{Statistics}

Variables were expressed as percentages or by their mean values $( \pm \mathrm{SD})$. The hypothesis was that there would be a significant change in relative $4 \mathrm{~h}$ renal ${ }^{123}$ I-MIBG uptake from baseline to 6 months after transplantation. This change was assessed by the Student's $t$-test for paired samples. Comparisons of kidney/background ratios at follow-up time points were assessed by one-sided ANOVA analysis. The $p$ values $\leq 0.05$ were considered significant. Statistical analysis was performed using SAS enterprise Guide 7.1.

\section{Results}

\subsection{Demographics and Clinical Characteristics}

Eleven recipients ( 6 men, 5 women) and their donors ( 7 men, 4 women) with an average age of 47 years ( \pm 16 years) and 52 years ( \pm 13 years), respectively, were included in the study (Table 1$)$. Besides the baseline data available in Table 1, there was no history of ischemic heart disease or cerebral vascular insult in either group. One follow-up scan was missed due to technical problems. No cases of graft rejection interfered with follow-up. Further detailed information of the 11 sets of donor/recipients with concern to kidney function, medication, and co-morbidity can be found in the Supplementary Material (Table S1). 
Table 1. Baseline clinical characteristics.

\begin{tabular}{ccc}
\hline & Donors & Recipients \\
\hline Age, years (SD) & $52(13)$ & $47(16)$ \\
\hline Gender, female, $n(\%)$ & $4(45)$ & $5(36)$ \\
\hline${ }^{51}$ Cr-EDTA clearance, $\mathrm{ml} / \mathrm{min}(\mathrm{SD})$ & $106(28)$ & $*$ \\
\hline Office blood pressure, systolic/diastolic, $\mathrm{mmHg}(\mathrm{SD})$ & $135(15) / 83(10)$ & $139(25) / 82(15)$ \\
\hline Diabetes, $n(\%)$ & $0(0)$ & $3(27)$ \\
\hline Hypertension, $n(\%)$ & $0(0)$ & $3(27)$
\end{tabular}

${ }^{51}$ Cr-EDTA: Chromium-51-Ethylenediaminetetraacetic acid; SD: Standard deviation. Values are shown as mean (SD) or numbers (\%). * Recipients did not have a ${ }^{51} \mathrm{Cr}$-EDTA plasma clearance performed routinely prior to transplantation as they, per definition, had an eGFR of $\leq 15 \mathrm{~mL} / \mathrm{min}^{*} 1.73 \mathrm{~m}^{2}$ and/or required chronic dialysis. The reasons to perform the kidney transplantation and medicine status figures are in the Supplementary Material (Table S1).

\subsection{Studies in Donors before Nephrectomy and in Transplant Recipients}

Within the group of donors, the relative renal ${ }^{123}$ I-MIBG uptake at 15 min was 6.8 and at $4 \mathrm{~h} 4.0$. The relative renal ${ }^{123}$ I-MIBG uptake, kidney/background ratio, for the donor kidney at baseline, 1, 3, and 6 months at both $15 \mathrm{~min}$ and $4 \mathrm{~h}$ is visualized in Figure 3 and all results from $15 \mathrm{~min}$ to $4 \mathrm{~h}$ are listed in Table 2.

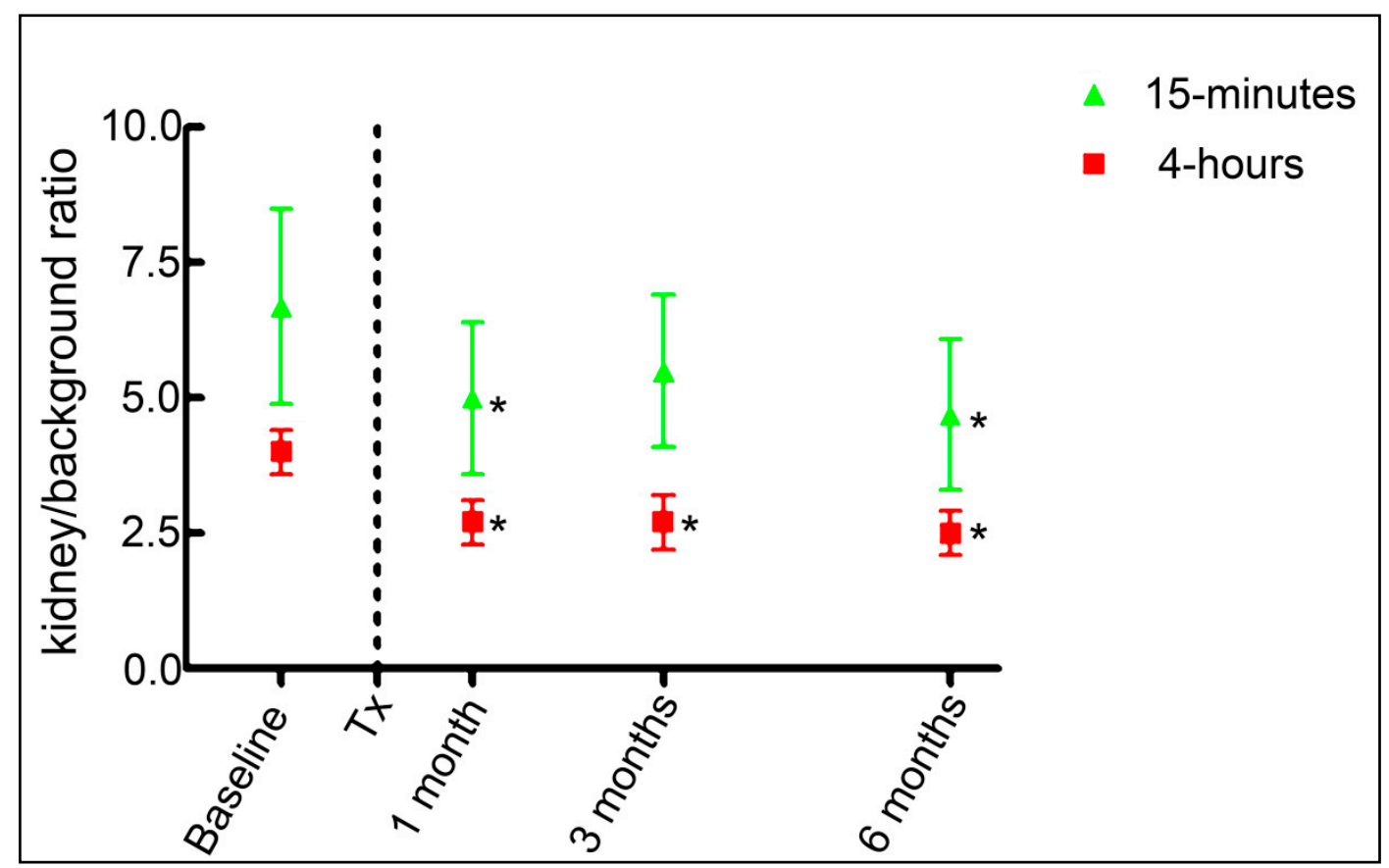

Figure 3. Relative ${ }^{123}$ I-MIBG uptake over time. Results are given as mean and standard deviation. Baseline indicates the value of the kidney within the donor, and follow-up time points are the same kidney within the recipient. 15-minutes and 4-hours indicates the relative ${ }^{123}$ I-MIBG uptake at these time points following intravenous injection of ${ }^{123} \mathrm{I}-\mathrm{MIBG}$. * indicates that the change is statistically significant $(p<0.05)$ from the baseline value. Tx; kidney transplantation. 
Table 2. Relative ${ }^{123}$ I-MIBG uptake and washout rate in the donor kidney over time.

\begin{tabular}{|c|c|c|c|c|c|c|}
\hline & $\begin{array}{c}\text { Baseline } \\
n=11 \\
\text { (SD) }\end{array}$ & $\begin{array}{c}1 \text { Month } \\
n=11 \\
\text { (SD) }\end{array}$ & $\begin{array}{l}3 \text { Months } \\
n=10 \\
\text { (SD) }\end{array}$ & $\begin{array}{l}6 \text { Months } \\
n=11 \\
\text { (SD) }\end{array}$ & $\begin{array}{l}\text { Change between Baseline } \\
\text { and } 6 \text { Months Mean } \\
(95 \% \mathrm{CI})\end{array}$ & $p$ Value \\
\hline \multicolumn{7}{|c|}{ Relative Ratio } \\
\hline $\begin{array}{c}15 \text { min } \\
\text { Kidney/Background }\end{array}$ & $\begin{array}{c}6.8 \\
(1.8)\end{array}$ & $\begin{array}{c}5.0 \\
(1.4)\end{array}$ & $\begin{array}{c}5.5 \\
(1.4)\end{array}$ & $\begin{array}{c}4.7 \\
(1.5)\end{array}$ & $\begin{array}{c}-2.3 \\
(-3.4 \text { to }-1.2)\end{array}$ & $0.0010 *$ \\
\hline $1 \mathrm{~h}$ Kidney/Background & $\begin{array}{c}4.8 \\
(0.9)\end{array}$ & $\begin{array}{c}3.3 \\
(1.0)\end{array}$ & $\begin{array}{c}3.6 \\
(0.8)\end{array}$ & $\begin{array}{c}3.1 \\
(0.6)\end{array}$ & $\begin{array}{c}-1.8 \\
(-2.7 \text { to }-0.9)\end{array}$ & $0.0012 *$ \\
\hline 2 h Kidney/Background & $\begin{array}{c}4.5 \\
(0.6)\end{array}$ & $\begin{array}{c}3.0 \\
(0.5)\end{array}$ & $\begin{array}{c}3.1 \\
(0.5)\end{array}$ & $\begin{array}{c}2.7 \\
(0.5)\end{array}$ & $\begin{array}{c}-1.9 \\
(-2.6 \text { to }-1.2)\end{array}$ & $0.0002 *$ \\
\hline 4 h Kidney/Background & $\begin{array}{c}4.0 \\
(0.4)\end{array}$ & $\begin{array}{c}2.7 \\
(0.4)\end{array}$ & $\begin{array}{c}2.7 \\
(0.5)\end{array}$ & $\begin{array}{c}2.5 \\
(0.4)\end{array}$ & $\begin{array}{c}-1.5 \\
(-2.0 \text { to }-1.0)\end{array}$ & $<0.0001$ * \\
\hline \multicolumn{7}{|c|}{ Washout Rate } \\
\hline $15 \mathrm{~min}$ to $1 \mathrm{~h}$ (\%/hour) & $\begin{array}{c}50.1 \\
(42.7)\end{array}$ & $\begin{array}{c}42.6 \\
(25.5)\end{array}$ & $\begin{array}{l}50.9 \\
(26.2)\end{array}$ & $\begin{array}{c}31.3 \\
(33.5)\end{array}$ & $\begin{array}{c}-16.9 \\
(-38.7 \text { to } 4.8)\end{array}$ & 0.1109 \\
\hline $15 \mathrm{~min}$ to $2 \mathrm{~h}$ (\%/hour) & $\begin{array}{c}26.8 \\
(21.8)\end{array}$ & $\begin{array}{c}23.4 \\
(14.0)\end{array}$ & $\begin{array}{l}31.0 \\
(10.4)\end{array}$ & $\begin{array}{c}27.5 \\
(12.8)\end{array}$ & $\begin{array}{c}-0.7 \\
(-14.8 \text { to } 13.4)\end{array}$ & 0.9067 \\
\hline $15 \mathrm{~min}$ to $4 \mathrm{~h}$ (\%/hour) & $\begin{array}{l}16.3 \\
(9.4)\end{array}$ & $\begin{array}{l}15.2 \\
(4.2)\end{array}$ & $\begin{array}{l}15.5 \\
(5.7)\end{array}$ & $\begin{array}{l}13.7 \\
(7.2)\end{array}$ & $\begin{array}{c}-3.3 \\
(-9.5 \text { to } 2.7)\end{array}$ & 0.2436 \\
\hline 1 to $2 \mathrm{~h}$ (\%/hour) & $\begin{array}{c}9.6 \\
(9.8)\end{array}$ & $\begin{array}{c}7.3 \\
(28.6)\end{array}$ & $\begin{array}{c}16.8 \\
(14.8)\end{array}$ & $\begin{array}{l}22.7 \\
(20.9)\end{array}$ & $\begin{array}{c}10.1 \\
(-10.0 \text { to } 30.3)\end{array}$ & 0.2731 \\
\hline 2 to $4 \mathrm{~h}$ (\%/hour) & $\begin{array}{c}9.4 \\
(5.0)\end{array}$ & $\begin{array}{c}7.8 \\
(11.9)\end{array}$ & $\begin{array}{l}1.5 \\
(9.6)\end{array}$ & $\begin{array}{l}1.8 \\
(6.0)\end{array}$ & $\begin{array}{c}-8.3 \\
(-15.1 \text { to }-1.4)\end{array}$ & $0.024 *$ \\
\hline \multicolumn{7}{|c|}{ Washout } \\
\hline $\begin{array}{l}\text { Washout } 15 \text { min to } 4 \mathrm{~h} \\
\qquad(\%)\end{array}$ & $\begin{array}{c}43.3 \\
(14.7)\end{array}$ & $\begin{array}{l}42.8 \\
(9.1)\end{array}$ & $\begin{array}{c}42.7 \\
(11.8)\end{array}$ & $\begin{array}{c}38.1 \\
(18.0)\end{array}$ & $\begin{array}{c}-6.7 \\
(-19.8 \text { to } 6.4)\end{array}$ & 0.2800 \\
\hline
\end{tabular}

Results are given as mean and standard deviation (SD). Relative ${ }^{123}$ I-MIBG uptake: Comparing the relative ${ }^{123}$ I-MIBG uptake before and 6 months following transplantation there is a significant reduction in estimation of renal sympathetic activity on all measurement points. Washout rate: Within each of the five individual time intervals there was no statistical difference between baseline values to 6 months following transplantation. K/B; kidney/background. CI: Confidence Interval. ${ }^{*}$ Statistical significant reduction compared to the baseline value.

The kidney/background ratio at 15 min post ${ }^{123}$ I-MIBG injection at pre-transplantation compared to that of the follow-up time points was significantly reduced at 1 and 6 months post-transplantation $(p<0.05)$. The $4 \mathrm{~h}$ kidney/background ratio was significantly decreased at 1,3 , and $6(p<0.005)$ months after transplantation compared to that pre-transplantation within the donor. Our results show a $29 \%$ to $33 \%$ reduction accordingly at 1 and 3 months, and a $41 \%$ reduction at 6 months in renal ${ }^{123}$ I-MIBG $4 \mathrm{~h}$ relative uptake following transplantation. Kidney/background ${ }^{123} \mathrm{I}-\mathrm{MIBG} 4 \mathrm{~h}$ uptake at 1,3 , and 6 months did not differ significantly from each other $(p=0.5)$. Washout rate was calculated for 5 individual time intervals. There were no statistical differences in ${ }^{123}$ I-MIBG washout rates (15 min to $1 \mathrm{~h} ; 15 \mathrm{~min}$ to $2 \mathrm{~h} ; 15 \mathrm{~min}$ to $4 \mathrm{~h} ; 1$ to $2 \mathrm{~h}$; or 2 to $4 \mathrm{~h}$ between pre-transplantation and 1, 3, and 6 months postoperatively) see Table 2 and Figure 4 for details. 


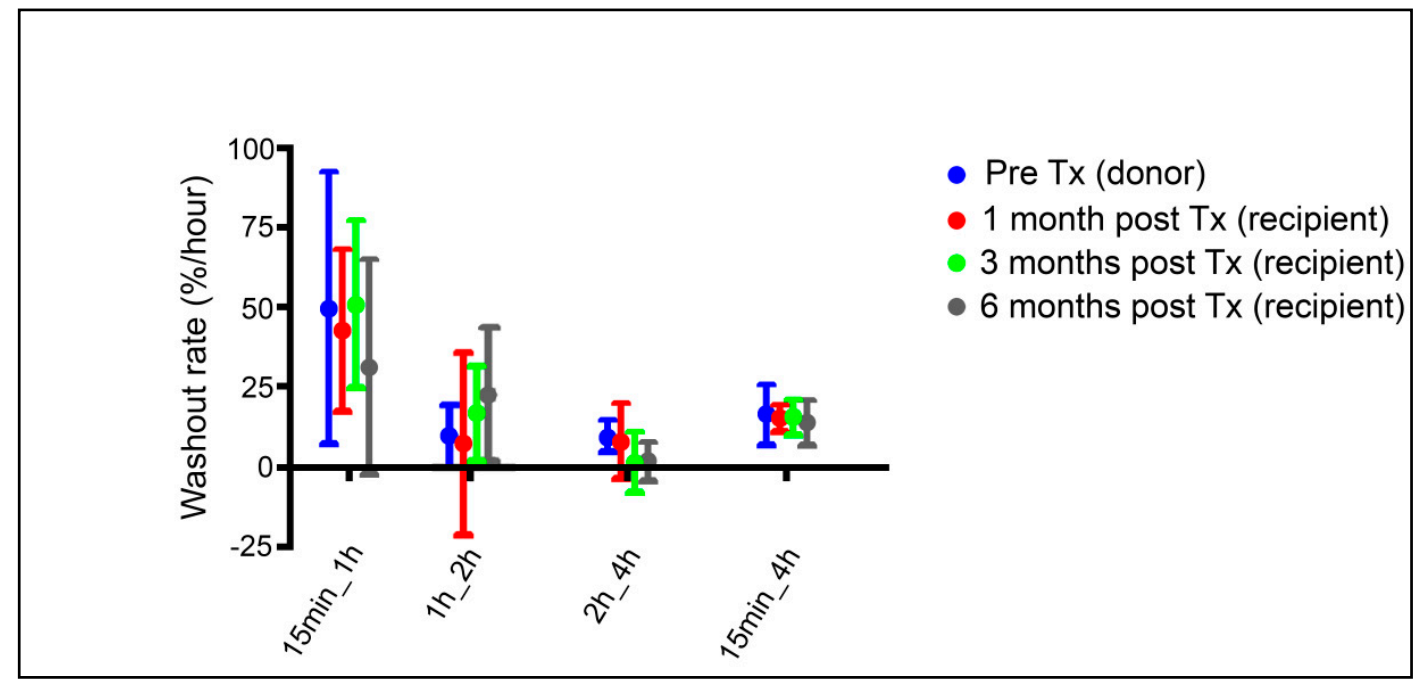

Figure 4. Washout rate of ${ }^{123}$ I-MIBG over time. Results are given as mean and standard deviation. There was no statistically significant change within any of the respective time intervals between baseline and times of follow up. Tx; kidney transplantation. The large difference between the $15 \mathrm{~min}$ to $1 \mathrm{~h}$ results compared to the other time intervals indicates that these early results reflect predominantly renal clearance of Metaiodobenzylguanidine (MIBG) via glomerular filtration rather than washout from sympathetic neurons.

\section{Discussion}

We hypothesized that the denervated transplanted kidney would display a markedly lower ${ }^{123}$ I-MIBG uptake compared to pre-transplantation due to the presumed lack of axonal neuronal input. Indeed, we found that the transplanted kidney/background ratio was reduced by $30-40 \%$ compared to the innervated kidney. These findings are intriguing; however, we cannot differentiate between the vascular, urinary, parenchymal, and neuronal components of the renal ${ }^{123}$ I-MIBG uptake. The compensatory hyperfiltration of the transplanted kidney might be a contributing component that would have to be considered in future studies. The reduced value is found already one hour after the tracer injection, and the value is almost unchanged after 2 and $4 \mathrm{~h}$. Furthermore, the kidney/background ratio was already reduced at one month to a level that was maintained after 3 and 6 months.

The objective of the present study was to examine the influence of procedural variables associated with ${ }^{123}$ I-MIBG imaging when a standardized technique was used to determine the kidney/background ratio. However, in the absence of guidelines for renal ${ }^{123}$ I-MIBG imaging, there has been limited standardization of the acquisition and quantitative analysis techniques, and published studies have involved small numbers of subjects and different reference standards. Therefore, in the attempt to evaluate the ${ }^{123}$ I-MIBG method's ability to assess renal denervation, we used an acquisition protocol adapted from cardiac Metaiodobenzylguanidine (MIBG) studies using early (15 min post-injection) planar and SPECT/CT and late (1, 2, and $4 \mathrm{~h}$ post-injection) planar imaging. While cardiac MIBG images at $15 \mathrm{~min}$ provide an indication of net extraction efficiency by sympathetic neurons (albeit with contamination by blood pool activity), this study revealed that renal counts at this time point predominantly reflected glomerular filtration and urinary excretion of MIBG. This is evident in the washout data in Figure 4 and Table 2, where the high calculated rate between $15 \mathrm{~min}$ and $1 \mathrm{~h}$ (as much as 6 times greater than the rate between 1 and $2 \mathrm{~h}$ ) undoubtedly reflects urinary excretion during the early time interval. Retrospectively, it is unfortunate that SPECT/CT was only performed at the early time point, in that the previously noted problem with urinary contamination limits the reliability of global or regional quantitation from these images.

The observed 30\% reduction in relative $4 \mathrm{~h}^{123} \mathrm{I}$-MIBG uptake in the recipient kidneys one month after transplantation in our study is in line with a previously published case report with measurement two 
weeks after auto-transplantation of a kidney [25]. Renal sympathetic neurons may however represent only a negligible portion of this ${ }^{123}$ I-MIBG uptake. Supporting this, is one study of liver transplant patients in which norepinephrine concentration in liver biopsies one month post-transplantation was only $1 \%$ of that in healthy normal livers [31]. In line with this and the interpretation by Dobrowlski and colleagues [24], scintigraphic values from the kidneys mainly comprise simultaneous uptake and storage of ${ }^{123}$ I-MIBG as well as an ongoing excretion of ${ }^{123}$ I-MIBG. The notable very low washout rate at 3 and 6 months between 2 and $4 \mathrm{~h}$ is due to some patients who had a negative washout in that time interval. It is yet to be established which time interval is the most optimal to measure washout rate. The assumed activity during the early phase following ${ }^{123}$ I-MIBG injection will represent a mixture of content in the pre-urine and washout from the renal tissue $[16,24]$. The washout rate of ${ }^{123}$ I-MIBG in kidneys might be difficult to untangle from filtration and, therefore, may be less relevant to estimating renal sympathetic activity.

\subsection{Strengths and Limitations}

In the present study we used the same kidney within the live kidney donor before transplantation as the control value, whereas in the only other study of renal ${ }^{123}$ I-MIBG scintigraphy in kidney transplant recipients, hypertensive non-transplant patients were used as controls [24]. Furthermore, by using attenuation correction we sought to eliminate the effect of the kidney being moved not only from one person to another, but also with an altered position within the body. The transplantation model implies a state of complete renal denervation, whereas in patients who have a catheter-based renal denervation, expected to be only partial, no significant change in renal ${ }^{123}$ I-MIBG scintigraphy uptake or washout have been demonstrated at 6 weeks after denervation [26].

It may be a limitation of our study that participants were kept on medications that possibly could influence the interpretation of the ${ }^{123}$ I-MIBG scintigraphy. In addition, an inherit challenge with imaging acquisition is the scatter from uptake by the liver with the right-sided native kidneys at baseline, and from the bladder with the transplanted kidneys. We assume that only denervation contributes to alterations in renal ${ }^{123}$ I-MIBG scintigraphy, but in the post-transplant phase patients are treated with immune suppressant medication that potentially may influence renal ${ }^{123}$ I-MIBG kinetics and sympathetic nerve function.

We acknowledge the absence of standardized methods for quantifying MIBG uptake in each of the three main components of the kidneys, namely, vascular, parenchymal (in which neuronal uptake is a part), and urinary uptake. Therefore, in the absence of independent measures of renal blood flow and urinary excretory function our results are limited to reflect MIBG uptake in these compartments as a whole and not specifically in sympathetic neurons.

Retrospectively, it is a limitation that we did not use SPECT/CT at all time points for determination of attenuation-corrected regional renal activity, which would have generated more accurate results compared to the use of the relative kidney uptake measurement, adapted from the planar heart/mediastinum ratio.

It is of course a limitation that this is a small study. Nevertheless, our results are consistently showing the same trend with statistical significance.

\subsection{Future}

In terms of the neuroanatomy of the nerves, Wallerian degeneration, neuronal regrowth, and the results in this study, it would be interesting to follow live-donor transplanted kidneys for a longer period in order to monitor changes in ${ }^{123}$ I-MIBG uptake. A recent study of patients who have had a heart transplantation shows that using three different catecholaminergic tracers simultaneously can evaluate the separate functions of the sympathetic nerve terminal such as; (a) neuronal transport, (b) vesicular storage; and (c) metabolic degradation [32]. It would be of interest to use this combined tracer technique to evaluate corresponding functions of denervated kidneys. 


\section{Conclusions}

To our knowledge, the present study is the first in the setting with ${ }^{123}$ I-MIBG uptake measurements of the same kidney before and after complete denervation due to live kidney transplantation. Live kidney transplantation was associated with a $30-40 \%$ reduction in the relative $4 \mathrm{~h}{ }^{123}$ I-MIBG uptake of the kidney. The renal ${ }^{123}$ I-MIBG scintigraphy method has to be further refined to fully establish the interpretation and its implications. A marker of renal nervous activity would be of great value in both chronic kidney disease, renal denervation, and renal transplantation, both in recipients and donors.

Supplementary Materials: The following are available online at http://www.mdpi.com/2075-4418/10/10/802/s1, Table S1. Detailed information of the 11 sets of donor/recipients with concern to kidney function, medication, and co-morbidity.

Author Contributions: Conceptualization, T.R., R.d.N., L.K.O., A.-L.K., L.E.B., M.F.-M., H.K., S.S.S., A.K., B.F.-R., J.H.S., P.H.; methodology, T.R., R.d.N., L.K.O., A.-L.K., L.E.B., M.F.-M., H.K., S.S.S., A.K., B.F.-R., J.H.S., P.H.; validation, T.R., R.d.N., L.K.O., A.-L.K., L.E.B., M.F.-M., H.K., S.S.S., A.K., B.F.-R., J.H.S., P.H.; formal analysis, P.H., R.d.N.; investigation, T.R., R.d.N., L.K.O., A.-L.K., L.E.B., M.F.-M., H.K., S.S.S., A.K., B.F.-R., J.H.S., P.H.; resources, T.R., R.d.N., L.K.O., A.-L.K., L.E.B., M.F.-M., H.K., S.S.S., A.K., B.F.-R., J.H.S., P.H.; data curation, L.K.O., T.R., R.d.N., P.H.; writing-original draft preparation, L.K.O.; writing-review and editing, T.R., R.d.N., L.K.O., A.-L.K., L.E.B., M.F.-M., H.K., S.S.S., A.K., B.F.-R., J.H.S., P.H.; project administration, L.K.O.; funding acquisition, all involved departments. All authors have read and agreed to the published version of the manuscript.

Funding: The study received funding from the Research Foundation of Rigshospitalet, Copenhagen, Denmark (Rigshospitalets Forskningspuljer) (No grant number).

Conflicts of Interest: J.H.S. received a research grant outside the present study from Medtronic (produces catheter-based renal denervation devices) and is a member of a Medtronic advisory board and speaker bureau. All other authors declare no conflict of interest. The funders had no role in the design of the study; in the collection, analyses, or interpretation of data; in the writing of the manuscript, or in the decision to publish the results.

\section{Appendix A}

\section{Attenuation Correction}

Since arms are not covering the patient's body in the anterior-posterior direction, it was assumed that the CT with arms above the head could be used for attenuation correction with arms along the patient's body. The CT-image was integrated in the anterior-posterior direction (z-direction) resulting in a CT water equivalent thickness $\mathrm{T}$ (including the patient table) given in $\mathrm{cm}$ by

$$
\mathrm{T}_{\text {water }}=\int(1+\mathrm{kCT}) \mathrm{dz}=\int_{0}^{\mathrm{T}} \frac{\mu-\mu_{\text {air }}}{\mu_{\text {water }}-\mu_{\text {air }}} \mathrm{dz}
$$

where $\mathrm{kCT}$ indicates the CT number divided by 1000. CT numbers (in Hounsfield Units $=\mathrm{HU}$ ) were converted into attenuation coefficients for $159 \mathrm{keV}$ photons by bilinear interpolation [33] with a transition point at $100 \mathrm{HU}$. Three calibration points were taken for air, water $\left(1.00 \mathrm{~g} / \mathrm{cm}^{3}\right)$, and Teflon $\left(2.20 \mathrm{~g} / \mathrm{cm}^{3}\right)$. The corresponding CT numbers were set at $-1000,0$, and $896 \mathrm{HU}$, respectively. The Teflon value is slightly $\mathrm{keV}$ dependent [34]. The corresponding narrow beam attenuation coefficients for $159 \mathrm{keV}$ photons were $0.000,0.1477$, and $0.2827 \mathrm{~cm}^{-1}$, respectively. The water and Teflon values were obtained from a double logarithmic fit and interpolation between 150 and $200 \mathrm{keV}$ on the data from the National Institute of Standards and Technology [35]. The geometric mean, also called the conjugated image, of the anterior A and (left-right mirrored) posterior image $p$ was calculated with $\mathrm{G}=\sqrt{ } \mathrm{AP}$. The attenuation factor $\mathrm{AC}$ was calculated for every pixel with:

$$
\mathrm{AC}=\mathrm{e}^{-\frac{1}{2} \int \mu \mathrm{dz}}
$$

This is derived for a point source position at an arbitrary position along the z-direction. The attenuation corrected geometric image $\mathrm{G}_{\mathrm{AC}}$ was created by multiplying $\mathrm{AC}$ with the geometrical mean, $\mathrm{G}_{\mathrm{AC}}=$ $G^{*}$ A. All calculations were performed in Matlab 2014b (Mathworks, Natick, MA, USA). 


\section{References}

1. Converse, R.L.; Jacobsen, T.N.; Toto, R.D.; Jost, C.M.; Cosentino, F.; Fouad-Tarazi, F.; Victor, R.G. Sympathetic Overactivity in Patients with Chronic Renal Failure. N. Engl. J. Med. 1992, 327, 1912-1918. [CrossRef] [PubMed]

2. Hausberg, M.; Kosch, M.; Harmelink, P.; Barenbrock, M.; Hohage, H.; Herne, K.K.; Dietl, K.H.; Rahn, K.H. Sympathetic Nerve Activity in End-Stage Renal Disease. Circulation 2002, 106, 1974-1979. [CrossRef] [PubMed]

3. Grassi, G.; Quarti-Trevano, F.; Seravalle, G.; Arenare, F.; Volpe, M.; Furiani, S.; Dell'Oro, R.; Mancia, G. Early Sympathetic Activation in the Initial Clinical Stages of Chronic Renal Failure. Hypertension 2011, 57, 846-851. [CrossRef] [PubMed]

4. Hansen, J.M.; Abildgaard, U.; Fogh-Andersen, N.; Kanstrup, I.-L.; Bratholm, P.; Plum, I.; Strandgaard, S. The Transplanted Human Kidney Does Not Achieve Functional Reinnervation. Clin. Sci. 1994, 87, 13-20. [CrossRef] [PubMed]

5. Norvell, J.E.; Weitsen, H.A.; Sheppek, C.G. The intrinsic innervation of human renal homotransplants. Transplantation 1970, 9, 168-176. [PubMed]

6. Gazdar, A.F.; Dammin, G.J. Neural Degeneration and Regeneration in Human Renal Transplants. N. Engl. J. Med. 1970, 283, 222-224. [CrossRef]

7. Krum, H.; Schlaich, M.P.; Whitbourn, R.; Sobotka, P.A.; Sadowski, J.; Bartus, K.; Kapelak, B.; Walton, A.; Sievert, H.; Thambar, S.; et al. Catheter-based renal sympathetic denervation for resistant hypertension: A multicentre safety and proof-of-principle cohort study. Lancet 2009, 373, 1275-1281. [CrossRef]

8. Esler, M.; Krum, H.; Sobotka, P.A.; Schlaich, M.P.; Schmieder, R.E.; Böhm, M.; Mahfoud, F.; Sievert, H.; Wunderlich, N.; Rump, L.C.; et al. Renal sympathetic denervation in patients with treatment-resistant hypertension (The Symplicity HTN-2 Trial): A randomised controlled trial. Lancet 2010, 376, 1903-1909. [CrossRef]

9. Bhatt, D.; Kandzari, D.; O’Neill, W. A Controlled Trial of Renal Denervation for Resistant Hypertension. J. Vasc. Surg. 2014, 60, 266. [CrossRef]

10. DiBona, G.F. The functions of the renal nerves. Rev. Physiol. Biochem. Pharmacol. 1982, 94, 75-181. [CrossRef]

11. DiBona, G.F. Sympathetic nervous system and the kidney in hypertension. Curr. Opin. Nephrol. Hypertens. 2002, 11, 197-200. [CrossRef] [PubMed]

12. Sisson, J.C.; Wieland, D.M. Radiolabeled meta-iodobenzylguanidine: Pharmacology and clinical studies. Am. J. Physiol. Imaging 1986, 1, 96-103. [PubMed]

13. Wieland, D.M.; Brown, L.E.; Rogers, W.L.; Worthington, K.C.; Wu, J.L.; Clinthorne, N.H.; Otto, C.A.; Swanson, D.P.; Beierwaltes, W.H. Myocardial imaging with a radioiodinated norepinephrine storage analog. J. Nucl. Med. 1981, 22, 22-31. [PubMed]

14. Torres, G.E.; Gainetdinov, R.R.; Caron, M.G. Plasma membrane monoamine transporters: Structure, regulation and function. Nat. Rev. Neurosci. 2003, 4, 13-25. [CrossRef] [PubMed]

15. Kline, R.C.; Swanson, D.P.; Wieland, D.M.; Thrall, J.H.; Gross, M.D.; Pitt, B.; Beierwaltes, W.H. Myocardial imaging in man with I-123 meta-iodobenzylguanidine. J. Nucl. Med. 1981, 22, 129-132.

16. Blake, G.; Lewington, V.; Zivanovic, M.; Ackery, D. Glomerular filtration rate and the kinetics of 123Imetaiodobenzylguanidine. Eur. J. Nucl. Med. Mol. Imaging 1989, 15, 618-623. [CrossRef] [PubMed]

17. Iwase, S. Clinical Assessment of the Autonomic Nervous System; Springer: New York, NY, USA; Berlin/Heidelberg, Germany, 2016.

18. Ito, S.; Kusuhara, H.; Yokochi, M.; Toyoshima, J.; Inoue, K.; Yuasa, H.; Sugiyama, Y. Competitive Inhibition of the Luminal Efflux by Multidrug and Toxin Extrusions, but Not Basolateral Uptake by Organic Cation Transporter 2, Is the Likely Mechanism Underlying the Pharmacokinetic Drug-Drug Interactions Caused by Cimetidine in the Kidney. J. Pharmacol. Exp. Ther. 2011, 340, 393-403. [CrossRef]

19. Wiseman, G.A.; Pacak, K.; O’Dorisio, M.; Neumann, D.R.; Waxman, A.D.; Mankoff, D.A.; Heiba, S.I.; Serafini, A.N.; Tumeh, S.S.; Khutoryansky, N.; et al. Usefulness of 123I-MIBG scintigraphy in the evaluation of patients with known or suspected primary or metastatic pheochromocytoma or paraganglioma: Results from a prospective multicenter trial. J. Nucl. Med. 2009, 50, 1448-1454. [CrossRef] 
20. Jacobson, A.F.; Senior, R.; Cerqueira, M.D.; Wong, N.D.; Thomas, G.S.; Lopez, V.A.; Agostini, D.; Weiland, F.; Chandna, H.; Narula, J.; et al. Myocardial iodine-123 meta-iodobenzylguanidine imaging and cardiac events in heart failure. Results of the prospective ADMIRE-HF (AdreView Myocardial Imaging for Risk Evaluation in Heart Failure) study. J. Am. Coll. Cardiol. 2010, 55, 2212-2221. [CrossRef]

21. De Marco, T.; Dae, M.; Yuen-Green, M.S.; Kumar, S.; Sudhir, K.; Keith, F.; Amidon, T.M.; Rifkin, C.; Klinski, C.; Lau, D.; et al. Iodine-123 metaiodobenzylguanidine scintigraphic assessment of the transplanted human heart: Evidence for late reinnervation. J. Am. Coll. Cardiol. 1995, 25, 927-931. [CrossRef]

22. Liu, B.; Codreanu, I.; Yang, J.; Servaes, S.; Zhuang, H. Diffuse Elevated MIBG Activity in the Renal Parenchyma Caused by Compromised Renal Blood Flow. Clin. Nucl. Med. 2014, 39, 1005-1008. [CrossRef] [PubMed]

23. Jordan, A.; Seltzer, M.; Siegel, A. 123I MIBG Appearance of Severe Renal Artery Stenosis. Clin. Nucl. Med. 2014, 39, 1003-1004. [CrossRef] [PubMed]

24. Dobrowolski, L.C.; Verberne, H.J.; van den Born, B.-J.H.; Ten Berge, I.J.; Bemelman, F.J.; Krediet, C.T.P. Kidney Transplant 123I-mIBG Scintigraphy and Functional Sympathetic Reinnervation. Am. J. Kidney Dis. 2015, 66, 543-544. [CrossRef] [PubMed]

25. Dobrowolski, L.C.; Eeftinck, D.W.S.; Idu, M.M.; van den Born, B.-J.H.; Verberne, H.J. Renal 123I-MIBG Scintigraphy Before and After Kidney Autotransplantation. Clin. Nucl. Med. 2015, 40, 810-811. [CrossRef]

26. Dobrowolski, L.; Schattenkerk, D.E.; Krediet, C.; Van Brussel, P.; Reekers, J.; van den Born, B.; Verberne, H. 4A.08: Assessing Modulations in Sympathetic Nerve Activity after Renal Sympathetic Denervation Using Renal 123i-Mibg Scintigraphy. J. Hypertens. 2015, 33 (Suppl. 1), e51. [CrossRef]

27. Menorca, R.M.; Fussell, T.S.; Elfar, J.C. Nerve physiology: Mechanisms of injury and recovery. Hand Clin. 2013, 29, 317-330. [CrossRef]

28. Wang, J.T.; Medress, Z.A.; Barres, B.A. Axon degeneration: Molecular mechanisms of a self-destruction pathway. J. Cell Biol. 2012, 196, 7-18. [CrossRef]

29. Verberne, H.J.; Feenstra, C.; De Jong, W.M.; Somsen, G.A.; Van Eck-Smit, B.L.F.; Sokole, E.B.; Eck-Smit, B.L.F. Influence of collimator choice and simulated clinical conditions on 123I-MIBG heart/mediastinum ratios: A phantom study. Eur. J. Nucl. Med. Mol. Imaging 2005, 32, 1100-1107. [CrossRef]

30. Dobbeleir, A.A.; Hambÿe, A.-S.E.; Franken, P.R. Influence of high-energy photons on the spectrum of iodine-123 with low- and medium-energy collimators: Consequences for imaging with 123I-labelled compounds in clinical practice. Eur. J. Nucl. Med. Mol. Imaging 1999, 26, 655-658. [CrossRef]

31. Kjaer, M.; Jurlander, J.; Keiding, S.; Galbo, H.; Kirkegaard, P.; Hage, E. No reinnervation of hepatic sympathetic nerves after liver transplantation in human subjects. J. Hepatol. 1994, 20, 97-100. [CrossRef]

32. Bravo, P.E.; Lautamäki, R.; Carter, D.; Holt, D.P.; Nekolla, S.G.; Dannals, R.F.; Russell, S.D.; Bengel, F.M. Mechanistic Insights into Sympathetic Neuronal RegenerationCLINICAL PERSPECTIVE. Circ. Cardiovasc. Imaging 2015, 8, e003507. [CrossRef] [PubMed]

33. Bai, C.; Shao, L.; Da Silva, A.; Zhao, Z. A generalized model for the conversion from ct numbers to linear attenuation coefficients. IEEE Trans. Nucl. Sci. 2003, 50, 1510-1515. [CrossRef]

34. Rhee, D.J.; Kim, S.-W.; Jeong, D.H.; Moon, Y.M.; Kim, J.K. Effects of the difference in tube voltage of the CT scanner on dose calculation. J. Korean Phys. Soc. 2015, 67, 123-128. [CrossRef]

35. Hubbell, J.H.; Seltzer, S.M. Tables of X-ray Mass Attenuation Coefficients and Mass Energy-Absorption Coefficients from $1 \mathrm{keV}$ to $20 \mathrm{MeV}$ for Elements $\mathrm{Z}=1$ to 92 and 48 Additional Substances of Dosimetric Interest. Available online: http://physics.nist.gov/PhysRefData/XrayMassCoef/tab4.html (accessed on 20 August 2015).

(C) 2020 by the authors. Licensee MDPI, Basel, Switzerland. This article is an open access article distributed under the terms and conditions of the Creative Commons Attribution (CC BY) license (http://creativecommons.org/licenses/by/4.0/). 